\title{
Electrochemical response of carbon aerogel electrodes in saline water
}

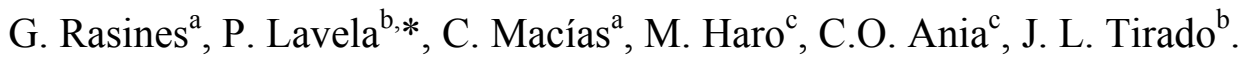 \\ a Nanoquimia S.L., P.L La Minilla, La Rambla, 14540 Córdoba, Spain. \\ ${ }^{\mathrm{b}}$ Laboratorio de Química Inorgánica, Universidad de Córdoba, Marie Curie, Campus de \\ Rabanales, 14071 Córdoba, Spain. \\ ${ }^{\mathrm{c}}$ Instituto Nacional del Carbón, CSIC, Apartado 73, 33080 Oviedo, Spain.
}

\begin{abstract}
Four carbon aerogels with varied micro/mesoporous texture were synthesized and their electrochemical response for the electro-adsorption of ions investigated in saline electrolyte. As a general trend, the ability of the electrodes to electrosorb ions depended on the microporosity, whereas the large pores (mesopores) had a strong influence on the kinetics of the electrosorption process. The aerogels exhibiting a well developed microporosity interconnected by a large mesoporous network showed large capacitance values and fast electro-adsorption kinetics. Indeed, the diffusion of the ionic species in solution controls the performance of the electrodes at high current loadings (or scan rates). Optimized electrode materials should combine pores within the micropore range to effectively electrosorb ions and large mesopore volumes for a fast diffusion of the ionic species in solution. An adequate meso/micropore ratio in the mesoporous carbon aerogels here reported allowed to record a capacitance value of $75.8 \mathrm{~F} \mathrm{~g} \mathrm{~g}^{-1}$.
\end{abstract}

*Corresponding author.

Tel/Fax: +34957218637

E-mail: iq1lacap@uco.es (P. Lavela) 


\section{Introduction}

In the last decades, great effort of the scientific community has focused on the design of new materials for energy storage and environmental applications. One of the most promising materials that are suitable on both applications are carbon gels, because of their controllable pore structure, high electrical conductivity, relatively low cost, and high surface area and porosity [6, 7, 8]. Indeed, since the first studies of Pekala and coworkers $[4,6]$ much research efforts have been devoted to anayze thee effect of the synthesis conditions on the morphological and porous structure of carbon gels and consequently on their performance $[9,10]$.

Due to such unique combination of physicochemical and structural properties, that may be conveniently adapted during the synthesis and processing, carbon gels possess great potential and versatility in electrochemical applications [11-14]. Their use as electrodes in capacitive deionization (CDI) systems for the electro-assisted removal of ionic species has been long investigated [15-17]. In the CDI process, the charged species are removed due to electrostatic interactions at the electrode/electrolyte interface during the polarization of the electrodes, which are held at a given potential difference. Driven by these electrostatic forces, the ions are forced to move to the opposite-charged electrode surface, thus large surface area electrodes are usually required for achieving high desalting capacities. Despite the simplicity of the process, CDI technology cannot currently compete with other processes (i.e, reverse osmosis, electro-dialysis) for water desalination, due to the lack of adequate electrode materials [15-17].

Typically high surface area is required for electrodes to form the electric double layer and increases the energy storage ability of an electrochemical device (i.e, supercapacitors) or the ions electrochemically removed from an aqueous solution. A 
number of studies have been reported on the electrochemical performance of a wide variety of carbon materials as electrodes in CDI (nanotubes, aerogels, activated carbons, and so-forth) [18-21]. Special emphasis has been paid to the use of carbon gels and other mesoporous materials as electrodes. Nevertheless, the a priori favorable textural characteristics of carbon aerogels do not guarantee an effective performance on electro-adsorption, since they usually present low current and ionic removal efficiencies. This poor performance of mesoporous carbon gels demands for further investigation to be improved.

The goal of this work was to evaluate the electrochemical response of several carbon aerogels in terms of their different textural characteristics, which have been tailored by adequately controlling the conditions during the synthesis. The influence of the resorcinol/catalyst ratio on the porosity of the obtained carbon aerogels was determined in order to optimize their micropore/mesopore volumes and average pore dimensions. The electrochemical response of the carbon aerogel electrodes has been analyzed in sodium chloride solutions of several concentrations, evaluating the electro-adsorption capacitance and kinetic properties of the prepared electrodes.

\section{Experimental}

\subsection{Sample preparation}

Four carbon aerogels were obtained by the sol-gel polymerization of resorcinol (R) and formaldehyde (F), in water (W), using carbonate as catalyst (C) and following a procedure inspired by the one proposed by Pekala and co-workers [6]. The resorcinol/catalyst $(\mathrm{R} / \mathrm{C})$ ratio was varied (i.e., 25, 50, 100 and 200) in order to produce samples with different porous texture, while the molar ratio $\mathrm{R} / \mathrm{F}$ was fixed at 0.5 , and 
the $\mathrm{R} / \mathrm{W}$ at 0.06 . The nomenclature of the samples was AGX, being $\mathrm{X}$ the corresponding $\mathrm{R} / \mathrm{C}$ value. Briefly, the precursors were mixed in sealed glass moulds under magnetic stirring and allowed to undergo gelation and aging in an oven at $40{ }^{\circ} \mathrm{C}$ for $24 \mathrm{~h}$ and $70^{\circ} \mathrm{C}$ for $120 \mathrm{~h}$. Subsequently a controlled water-acetone exchange was carried out, and then the pieces were dried under $\mathrm{CO}_{2}$ supercritical conditions. Finally, the aerogels were pyrolysed at $850^{\circ} \mathrm{C}$ under nitrogen atmosphere under a controlled heating program described elsewhere [22].

\subsection{Textural characterization}

The nanotexture of the carbon materials was characterized by $\mathrm{N}_{2}$ adsorption-desorption isotherms at $-196^{\circ} \mathrm{C}$ (ASAP 2010, Micromeritics). Before the experiments, all the samples were outgassed under primary vacuum at $120^{\circ} \mathrm{C}$ (heating rate $5{ }^{\circ} \mathrm{C} / \mathrm{min}$ ) overnight. The isotherms were used to calculate the specific surface area, $\mathrm{S}_{\mathrm{BET}}$, total pore volume, $\mathrm{V}_{\mathrm{T}}$, and pore size distributions using the density functional theory (DFT) approach; the micropore volume was also evaluated by the DR method [23].

\subsection{Electrochemical response of the carbon aerogels}

All electrochemical measurements were conducted in a three electrode Swagelok ${ }^{\mathrm{TM}}$ type cell consisting of a graphite current collector to house the working electrode, a $\mathrm{Hg} / \mathrm{Hg}_{2} \mathrm{SO}_{4}$ reference electrode and a platinum counter electrode. The working electrode was prepared by mixing active material (90\%) and PVDF binder $(10 \%)$ on a $13 \mathrm{~mm}$ titanium disk (using $\mathrm{N}$-methyl pyrrolidone as solvent). This electrode was eventually dried at $50^{\circ} \mathrm{C}$ overnight and subsequently two hours at $80^{\circ} \mathrm{C}$. The electrode was cooled and vacuum-impregnated before assembling. The electrolyte was sodium chloride dissolved in distilled water for all experiments, with concentrations ranging from 1.5 to $35 \mathrm{~g} / \mathrm{L}$. Several electrochemical measurements were performed on each carbon aerogel electrode, using a computer controlled potentiostat/galvanostat (Biologic 
VMP mutichannel potentiostat). Cyclic voltammetry was conducted between -0.5 and $-0.5 \mathrm{~V}$ vs reference electrode for several sweep rates ranging from 0.5 to $50 \mathrm{mV} / \mathrm{s}$. The capacitance of each electrode was evaluated from cyclic voltammetry using the relationship $\mathrm{C}=\mathrm{I} / \mathrm{v} \mathrm{m}$, where $\mathrm{I}(\mathrm{mA})$ is the average current in the applied potential window, $\mathrm{v}$ is the applied sweep rate in $\mathrm{mV} / \mathrm{s}$ and $\mathrm{m}$ is the mass of the electrode (normalized capacitance per unit mass of electrode). Chronocoulometric curves were performed by inducing a pulse of constant potential $\left(250 \mathrm{mV}\right.$ vs $\left.\mathrm{Hg} / \mathrm{Hg}_{2} \mathrm{SO}_{4}\right)$ for $100 \mathrm{~s}$ and recording the current transient. Electrochemical impedance spectroscopy (EIS) of the prepared carbon aerogel electrodes was used to analyze the kinetic properties of the electro-sorption reaction. These measurements were recorded in an Autolab PGSTAT12 system, using a voltage signal of $5 \mathrm{mV}$ vs equilibrium potential (i.e., open circuit potential, which ranged from 0.4 to $0.6 \mathrm{~V}$ vs reference electrode), over the frequency range $25 \mathrm{kHz}$ to $10 \mathrm{mHz}$ at the equilibrium potential.

\section{Results and discussion}

\subsection{Nanotextural characterization of the electrodes}

Analysis of the porous features of the synthesized carbon aerogels by $\mathrm{N}_{2}$ adsorption isotherms (Figure 1) showed a strong influence of the $\mathrm{R} / \mathrm{C}$ ratio in the textural characteristics of the obtained aerogels (cf. Table 1). For instance carbon AG25 exhibits a type I isotherm according to BDDT classification [24], indicating the predominance of microporosity when low $\mathrm{R} / \mathrm{C}$ ratio are used in the synthesis. The small hysteresis loop in the desorption branch at $\mathrm{p} / \mathrm{p}_{\mathrm{o}}$ ca. 0.5 points out the contribution of mesopores of small sizes for this material, which is in agreement with the expected porous structure of a polymeric gel obtained using a low $\mathrm{R} / \mathrm{C}$ ratio [10]. As the $\mathrm{R} / \mathrm{C}$ was increased, the carbon aerogels displayed a much more developed mesoporous structure showing type IV nitrogen adsorption isotherms -with somewhat type I character due to 
the presence of a non negligible microporosity-, with prominent hysteresis loops at high relative pressures. Both the position of the hysteresis loops and the corresponding pore volume are strongly dependent on the $\mathrm{R} / \mathrm{C}$ ratio. The shape of the hysteresis loops was also different for the synthesized aerogels; samples AG50 and AG100 show a type H2 [23] loop, suggesting some kinetic constrictions during desorption of ink-bottle shaped mesopores. In contrast, sample AG200 displayed a characteristic H1 desorption loop, where the adsorption and desorption branches are rather vertical and almost parallel over the gas uptake, which indicates a rather narrow distribution of pore sizes (within the mesopore range). Thus it seems that the $\mathrm{R} / \mathrm{C}$ ratio controls the micro/mesopore balance in the samples, the average pore width and the interconnectivity of the porous network. A fast polycondensation of the reactants (defined by low $\mathrm{R} / \mathrm{C}$ ratio) favors the formation of micro- and narrow mesopores (low micro to mesopore ratio); in contrast high $\mathrm{R} / \mathrm{C}$ give rise to large pore volumes due to the formation of clusters of large sizes with a highly cross-linked structure [25]. These observations are in good agreement with the analysis of the pore size distribution presented in Figure 1b, where a straightforward correlation is evident between the average pore size and the $\mathrm{R} / \mathrm{C}$ ratio. Low amounts of catalysts (i.e., high $\mathrm{R} / \mathrm{C}$ ratio) favored the formation of large mesopores (ca. $14 \mathrm{~nm}$ for AG200) with rather monodispersed distribution of pore sizes (PSD) for all the aerogels in the mesopore range with the exception of sample AG25. In this case, a bimodal PSD was obtained, with quite a broad distribution of pore widths between 1 and $5 \mathrm{~nm}$. The contribution of mesopores significantly increased for AG50, AG100 and AG200, which showed PSD centered at ca. 5, 7 and $14 \mathrm{~nm}$, respectively. These results are in good agreement with previous works reported in the literature on the porosity development of carbon gels prepared with various R/C catalysts [26, 27]. Data also showed a non-linear correlation between the surface and the $\mathrm{R} / \mathrm{C}$ ratio; the 
sharp increase in the surface area at low R/C values is gradually lowered until it reaches an almost limiting value at high $\mathrm{R} / \mathrm{C}$ ratio. This suggests that the polycondensation of the reactants under low amounts of catalyst favor the formation of mesopores rather than micropores (which contribution to the surface area is higher). This is also supported by the micropore volumes obtained by the DR method applied to the nitrogen adsorption isotherms (Table 1), which are higher for the low $\mathrm{R} / \mathrm{C}$ gels and reach an almost constant value for sample AG100 and AG200. This finding is clearly illustrated in Figure 2. The notorious changes observed in the porous structure of the studied samples must be reflected in remarkable differences in their electrochemical performance.

\subsection{Electrochemical response of the electrodes}

Cyclic voltammetry was used to examine the influence of the porosity of the carbon aerogel electrodes on their electrochemical performance in a saline solution. Figure 3 shows the cyclic voltammograms in a $10 \mathrm{~g} / \mathrm{L} \mathrm{NaCl}$ electrolyte solution recorded at several sweep rates. As expected, the capacitance decreased with an increase in the scan rate, although important differences were evident for the four studied materials. At the lowest scan rates (ca. 0.5 and $1 \mathrm{mV} / \mathrm{s}$ ), the curves showed a nearly rectangular-shaped profiles ascribable to the pure capacitive behavior when ions are effectively electro-adsorbed/desorbed within the electric double layer at the electrode surface [28]. It is interesting to remark that at potentials above $+200 \mathrm{mVs}$ vs $\mathrm{Hg} / \mathrm{Hg}_{2} \mathrm{SO}_{4}$, an anodic current leap likely related to pseudo-faradaic reactions -including the electrolyte decomposition- was observed [28, 29]. This effect was more pronounced for sample AG200, and particularly in the first cycle, gradually decreasing upon subsequent cycles. A similar anomalous electrochemical behavior of carbon electrodes on the first cycle has been reported by Itoi and co-workers [30], and explained as the 
anodic oxidation of the carbon electrode during the first polarization cycle in sulfuric electrolyte, based on the high reactivity of their zeolites-templated carbon electrode. Experiments carried out in sulfuric medium did not show the broad peaks characteristics of the presence of oxygen-containing functional groups at the edges sites of the carbon electrode [22]. Thus, we interpret this singular behavior in terms of a restricted accessibility of the ions during polarization, likely attributed to the insufficient electrode wettability.

On increasing the scan rate, the shape of the voltammogram was flattened and the capacitance values drastically decreased for all the materials, the effect being particularly remarkable for sample AG25 which displayed the lowest mesopore volume (Table 1). This fact reveals that at high sweep rates, the ohmic resistance for electrolytic ions migration into the pores largely affects the double layer formation [31] despite the large mesoporosity of these electrodes and the relatively moderate values of the fast scan rates investigated (i.e., 5 and $10 \mathrm{mV} / \mathrm{s}$ ).

These observations point out that two different regimes govern the electrochemical performance of the electrodes. At low scan rates, no restrictions in the ions mobility are expected, thus the capacitance values should be mainly correlated with the textural features of the electrodes. On the other hand at high scan rates, the capacitance would be expected to depend also on the ability of the electrode materials to deliver a fast ion migration within the porous network (i.e., on the accessible pores).

In fact, it is generally considered that pores which dimension are smaller than a specific cut-off width do not contribute to the total capacity $[32,33]$, thus it is important to tailoring the (micro)pore size of the electrode material to match the dimensions of the electrolyte. Additionally, it is also widely believed that when operating at high scan rate 
conditions, ions can only penetrate the large mesopores and thus only a fraction of the overall porosity is effective in the formation of the double layer [33,34]. Consequently, most of the microporous electrodes usually underperform at fast polarization conditions, for which the use of mesoporous electrodes (including carbon aerogels) has become very attractive in electrochemical applications $[1,5,4,11,20,22]$. Capacitance value of 133.9 and $75.8 \mathrm{Fg}^{-1}$ were respectively recorded at 0.5 and $1 \mathrm{mV} / \mathrm{s}$ rate for AG200. This values are higher than those reported in the literature for related carbon aerogels $[35,36]$.

To throw some light on this issue, we have tried to correlate the electrochemical performance of carbon aerogel electrodes with their porosity and the kinetics of the ions electrosorption depending on the operating conditions applied. Table 1 shows that capacitance of the carbon aerogel electrodes correlates to the microporosity of the carbon aerogel electrodes, excepting for AG200. Likely, the high capacitance value achieved for the latter sample must be attributed to the positive contribution of the high surface area and mesopores volume to the double layer capacitance. The decrease of the capacitance with increasing the sweep rate is notorious for the four materials investigated, regardless their outstanding differences in mesopore and total pore volumes (Table 1). It clearly indicates that the restricted accessibility under high sweep rates affects to the ionic diffusion through both micro and mesopores.

The electrochemical response of the carbon electrodes was also investigated by impedance spectroscopy and chronoamperometry. The capacitance values were calculated from the imaginary part (Z”) obtained from the impedance spectra, according to the following equation [37]: 
where $\mathrm{C}$ is the capacitance in $\mathrm{F} / \mathrm{g}, \omega$ is the frequency in hertzs and $\mathrm{Z}$ " is the imaginary part of the mass normalized impedance spectrum.

Figure 4 illustrates the evolution of the capacitance versus frequency; a sharp decrease in capacitance with the increase in frequency was obtained for all the gels, with values close to zero at frequencies higher than $1 \mathrm{~Hz}$ for all the materials with the exception of AG25 (ca. above $0.1 \mathrm{~Hz}$ ). This indicates that the electrolyte ions cannot penetrate into the pores at fast charge rates (high frequency values). Bearing in mind the large mesopore sizes and volumes of the carbon electrodes (Figure 1), and the dimensions of the solvated ions in solution [38], it is very unlikely that the ions cannot penetrate the big pores of the carbon aerogel electrodes. Thus, the poor electrochemical performance has to be attributed to the lack of 'effective pores' for electrosorption of ions. On the other hand, the role of mesopores on the electrosorption kinetics -particularly when operating at high scan rates or frequencies- cannot be neglected. Indeed, the superior capacitive performances of AG50, AG100 and AG200 at high frequencies over AG25 (Figure 4) can be ascribed to their larger mesopore sizes and volumes. Comparatively, the negligible differences between the former carbons (R/C 50, 100 and 200) indicate that the kinetics of the electrolyte diffusion is equally favored for the three materials despite their average mesopore width and volumes. For AG25, the slow electrosorption kinetics of AG25 is explained due to the large contribution of micropores to the overall porosity [38].

Impedance spectra were recorded in order to clarify the dominant time-dependent electrochemical processes that take place in the carbon aerogel electrodes, and 
particularly to gain insight on the contribution of the mesopore and micropore to the electrochemical capacitance. Nyquist plots corresponding to the carbon aerogel electrodes are shown in Figure 5, and the main parameters obtained from the modeling of the impedance spectra are compiled in Table 2.

The high-frequency response $(>10 \mathrm{kHz})$ is dominated by the bulk resistance of the solution $\left(\mathrm{R}_{\text {solution }}\right)$ and, whereas the $1 \mathrm{~Hz}$ to $10 \mathrm{kHz}$ regime represents the resistance due to ionic migration inside the porosity of the electrode $\left(\mathrm{R}_{\text {porosity }}\right)$, and the region below $1 \mathrm{~Hz}$ represents the electrochemical capacitance of the electrode $[38,39]$. It can be observed that the size of the semicircle decreased monotonically with the $\mathrm{R} / \mathrm{C}$ ratio; given the correlation of this $\mathrm{R} / \mathrm{C}$ parameter with the micro/mesopore ratio of the carbon aerogels, this indicates that the contribution of ionic resistance due to the mobility of ions to enter the pores is largely reduced when the electrode material posses a welldeveloped mesoporosity. In other words, microporosity may become a barrier for ions to enter the pores, unless connected to a network of large (transport) pores. Data in Table 2 shows that for a constant electrolyte concentration (i.e, $10 \mathrm{~g} / \mathrm{L}$ ), both the $\mathrm{R}_{\text {solution }}$ and the $\mathrm{R}_{\text {porosity }}$ decreased with the $\mathrm{R} / \mathrm{C}$ ratio, although this was more evident for the latter. Besides, the straight line at low frequencies (Warburg impedance characteristic of capacitive behavior) [40] also becomes more steep for the highly mesoporous carbon electrodes, indicating the faster diffusion of species for these materials. Moreover, for a given carbon electrode such as AG200, these parameters decreased sharply with the ionic concentration in solution (Table 2).

The kinetics of the electro-adsorption process during polarization of the electrodes was alternatively determined by chronocoulometry, by integrating the current response during the application of a short potential pulse as a function of time. The process involves anodic polarization to evaluate the migration of chloride anions towards the 
carbon aerogel electrodes surface. The higher the slope, the shorter the relaxation time constant required for reaching the equilibrium. Figure 6a shows the chronocoulometric plots - normalized vs the mass of the electrodes - corresponding to the carbon aerogels polarized in $10 \mathrm{~g} / \mathrm{L} \mathrm{NaCl}$ solutions. The relevant time constants were quantified by applying the following equation to the current transient curve [38]:

$-\ln \left(1-\frac{Q}{Q_{n}}\right)=\frac{t}{R C}$

where $t$ is the time of pulse, $Q_{0}$ is the electrode's charge at the equilibrium; $\mathrm{R}$ and $\mathrm{C}$ the resistance and capacitance of the electrode, respectively. The relaxation time constant $\tau$ is equivalent to the product $\mathrm{RC}$. The linearity of this equation is effective at least for short times and hence the time constant $(\tau=\mathrm{RC})$ can be calculated from the slope.

The time constants corresponding to the series of carbon aerogels studied are shown in Table 3. The time constant is expected to depend on the ion radii and the average pore dimensions of the electrodes. In our case, the same electrolyte was used (i.e., $\mathrm{NaCl}$ ) for all the studies, thus the evaluation of this parameter will be indicative of the role of the porous features (i.e., ratio Vmicro/Vmeso) of the carbon electrodes on the electrosorption kinetics. It can be clearly seen in Figure $6 \mathrm{~b}$ that, as expected, the electro-adsorption into the carbon electrodes is hindered in the electrodes with small pore dimensions (i.e., AG25) as revealed by the decrease in the transient's relaxation time constant with the mesopore size. Thus, a slow electro-adsorption kinetics occurs when microporosity is dominant on the carbon electrodes. The ionic resistance was lowered in the mesoporous electrodes owing to the interconnected porous network, but in fact, the capacity was almost exclusively dependent on the micropore volume. Based on these results, it can be concluded that the use of mesoporous electrodes has a positive effect on the electrosorption kinetics, whereas microporous electrodes have a positive 
effect on the capacity (lower capacitance values are generally obtained for mesoporous electrodes due to non-effective pore dimensions). The ideal electrode material should include mesopores to guarantee the fast access to micropores (i.e., high current efficiency) that act as main contributors of the ions electroadsorption.

Eventually, the effect of the electrolyte concentration was evaluated in sample AG200. Figure 7 evidences a progressive increase in capacitance and a more rectangular-shaped voltammograms when the electrolyte concentration was increased to $35 \mathrm{~g} / \mathrm{L}$. This shows that both the decrease in the bulk solution resistance and the availability of a larger number of ionic species to form the electrical double layer have a remarkable effect in the electrochemical response of the carbon aerogel electrodes. The inset in Figure 7 also evidences that the increase in the capacitance is non-linear and a saturation limit is reached at high $\mathrm{NaCl}$ contents. The effect of solution concentration on the charging rate of the electrodes was also investigated by chronocoulometry for sample AG200 (Figure 8). The time constants for this process are also compiled in Table 3 . These measurements confirmed that the electrosorption kinetics is enhanced with the electrolyte concentration, due to the lower bulk solution resistance; consequently longer relaxation times are needed to reach the equilibrium in the current transient for low ionic concentrations (Table 3).

\section{Conclusions}

The electrochemical response of a series of carbon aerogel electrodes has been investigated in a saline electrolyte and analyzed in terms of the micro/mesoporous texture. The carbon aerogels were synthesized using an increasing $\mathrm{R} / \mathrm{C}$ ratio, leading to high surface areas and pore volumes, and tailored PSD within the micropore and the 
mesopore range. We have observed that the ability of the electrodes to electrosorb ions depends strongly to the micropore volume, whereas the large pores (mesopores) have a strong influence on the kinetics of the electrosorption process.

As a general trend, those carbon aerogels exhibiting a well developed microporosity interconnected by an adequate mesoporous network showed large capacitance values and faster electro-adsorption kinetics. A capacitance value as high as $75.8 \mathrm{Fg}^{-1}$ was recorded for AG200 at $1 \mathrm{mV} / \mathrm{s}$ rate. This value is higher than that reported in the literature for related carbon aerogels. Indeed, the diffusion of the ionic species in solution controls the performance of the electrodes at high current loadings (or scan rates). Impedance spectroscopy and chronocoulometry demonstrated that narrow mesopores can hinder the accessibility of ions to the microporosity of the electrodes, leading to a slow electro-adsorption.

Based on these results we suggest that neither microporous electrodes with large surface area nor highly mesoporous materials are necessarily the best choice for electroadsorption applications. The first ones are associated to high capacitance values but present relatively slow electro-adsorption kinetics, whereas mesoporous carbon aerogels have fast charging rates but often lack from optimized pore dimensions to efficiently electrosorb ions. Nevertheless, mesoporous carbon aerogel electrodes should not be excluded for electrochemical applications, provided that their porous structure can be easily adapted to an adequate meso/micropore ratio so as to obtain materials with optimized multiporous structure.

\section{Acknowledgements}


The authors are indebted to the Spanish MARM (grant 083/RN08/03.3) and MICINN (grants CTM2008-01956 and CTM2011-23378) for financial support. Technical support of M.C. Mohedano is also acknowledged. MH thanks CSIC for a postdoctoral contract.

\section{References}

[1] Y.J. Lee, J.C. Jung, S. Park, J.G. Seo, S.H. Baeck, J.R. Yoon, J. Yi, , I.K. Song, Preparation and characterization of metal-doped carbon aerogel for supercapacitor, Curr. Appl. Phys. 10 (2010) 947-951.

[2] G.M. Pajonk, Aerogel Catalysts, Appl. Catal. 72 (1991) 217-66.

[3] P. Lavela, F. Nacimiento, G.F. Ortiz, J.L. Tirado, Sn-Co-C composites obtained from resorcinol-formaldehyde gel as anodes in lithium-ion batteries, J. Solid State Electrochem.;14 (2010) 139-148.

[4] R.W. Pekala, J.C. Farmer, C.T. Alviso, T.D. Tran, S.T. Mayer, J.M. Miller, B. Dunn, Carbon aerogels for electrochemical applications, J. Non-Cryst. Solids 225 (1998) 74-80.

[5] J.C. Farmer, D.V. Fix, G.V. Mack, R.W. Pekala, J.F. Poco, Capacitive deionization of $\mathrm{NH}_{4} \mathrm{ClO}_{4}$ solutions with carbon aerogel electrodes, J Appl. Electrochem. 26 (1996) 1007-1018.

[6] R.W. Pekala, Organic Aerogels from the Polycondensation of Resorcinol with Formaldehyde, J. Mater. Sci. 24 (1989) 3221-3227.

[7] R.W. Pekala, C.T. Alviso, J.D. Lemay, Chemical Processing of Advanced Materials, John Wiley and Sons, New York, 1992. 
[8] D.C. Wu, R.W. Fu, S.T. Zhang, M.S. Dresselhaus, G. Dresselhaus, Preparation of low-density carbon aerogels by ambient pressure drying, Carbon;42 (2004) 2033-9.

[9] T. Horikawa, J. Hayashi, K. Muroyama, Size control and characterization of spherical carbon aerogel particles from resorcinol-formaldehyde resin. Carbon 42 (2004) 169-75.

[10] S.A. Al-Muhtaseb, J.A. Ritter, Preparation and properties of resorcinolformaldehyde organic and carbon gels, Adv. Mater. 15 (2003) 101-114.

[11] H.H. Jung, S.W. Hwang, S.H. Hyun, K.H. Lee, G.T Kim, Capacitive deionization characteristics of nanostructured carbon aerogel electrodes synthesized via ambient drying, Desalination;216 (2007) 377-385.

[12] C.J. Gabelich, T.D. Tran, I.H. Suffet, Electrosorption of Inorganic Salts from Aqueous Solution Using Carbon Aerogels, Environ. Sci. Technol.; 36 (2002)30103019.

[13] S.W. Hwang, S.H. Hyun, Capacitance control of carbon aerogel electrodes, Journal of Non-Cryst. Solids;347 (2004) 238-245.

[14] P. Xu, J.E. Drewes, D. Heil, G. Wang, Treatment of brackish produced water using carbon aerogel-based capacitive deionization technology, Water Res. 42 (2008) 26052617.

[15] M.A. Anderson, A.L. Cudero, J. Palma, Capacitive deionization as an electrochemical means of saving energy and delivering clean water. Comparison to present desalination practices: Will it compete?, Electrochim Acta. 55(2010) 3845-56. 
[16] Y. Oren, Capacitive delonization (CDI) for desalination and water treatment - past, present and future (a review), Desalination. 228(2008) 10-29.

[17] Q. Daoduo, Z. Linda, H. Eric, Electrosorption: An alternative option for desalination, Res. J. Chem. Environ. 11(2007) 92-5.

[18] H.B. Li, Y. Gao, L.K. Pan, Y.P. Zhang, Y.W. Chen, Z. Sun, Electrosorptive desalination by carbon nanotubes and nanofibres electrodes and ion-exchange membranes, Water Res.;42 (2008) 4923-8.

[19] H.J. Oh, J.H. Lee, H.J. Ahn, Y. Jeong, Y.J. Kim, C.S. Chi, Nanoporous activated carbon for capacitive deionization of aqueous solution, Thin Solid Films 515 (2006) $220-5$.

[20] L.X. Li, L.D. Zou, H.H. Song, G. Morris, Ordered mesoporous carbons synthesized by a modified sol-gel process for electrosorptive removal of sodium chloride, Carbon 47 (20093) 775-81.

[21] K. Dai, L. Shi, D. Zhang, J. Fand, $\mathrm{NaCl}$ adsorption in multiwalled carbon nanotubes/active carbon combination electrode, Chem. Eng. Sci. 1 (2006) 428-33.

[22] M. Haro, G. Rasines, C. Macías, C.O. Ania, Stability of a carbon gel electrode when used for the electro-assisted removal of ions from brackish water. Carbon 49 (2011) 3723-3730.

[23] Rouquerol F, Rouquerol J, Sing K. Adsorption by Powders and Porous Solids Academic Press, London, 1999.

[24] B. Brunauer, L.S. Deming, W.E. Deming, E. Teller, On a theory of the van der Waals adsorption of gases, J. Am. Chem. Soc.;62 (1940) 1723-1732. 
[25] H. Tamon, H. Ishizaka, T. Araki, M. Okazaki, Control of mesoporous structure of organic and carbon aerogels, Carbon 36 (1998) 1257-1262.

[26] N. Job, A. Thery, R. Pirard, J. Marien, L. Kocon, J.N. Rouzaud, , F. Beguin, J. P. Pirard, Carbon aerogels, cryogels and xerogels: Influence of the drying method on the textural properties of porous carbon materials. Carbon 43 (2005) 2481-2494.

[27] H. Tamon, H. Ishizaka, M. Mikami, M. Okazaki, Porous structure of organic and carbon aerogels synthesized by sol-gel polycondensation of resorcinol with formaldehyde, Carbon 35 (1997) 791-796.

[28] C.T. Hsieh, H. Teng, Influence of oxygen treatment on electric double-layer capacitance of activated carbon fabrics. Carbon;40 (2002) 667-674.

[29] H. Pröbstle, M. Wiener, J. Fricke, Carbon aerogels for electrochemical double layer capacitors, J. Porous Mater.;10 (2003) 213-222.

[30] $\mathrm{H}$ Itoi, $\mathrm{H}$ Nishihara, $\mathrm{T}$ Ishi, $\mathrm{R}$ Berenguer, $\mathrm{T}$ Kyotani, Anomalous large electrochemical capacitance of zeolite-templated carbon in aqueous media, Carbon 2011, extended Abstract n 290, Shanghai, 2011.

[31] H. Liu, K. Wang, H. Teng, A simplified preparation of mesoporous carbon and the examination of the carbon accessibility for electric double layer formation. Carbon 43(2005) 559-566.

[32] K.L. Yang, T.Y. Ying, J.Sátira, Electrosorption of Ions from Aqueous Solutions by Carbon Aerogel: An Electrical Double-Layer Model, Langmuir, 17 (2001) 1961-1969. 
[33] C.O. Ania, J. Pernak, F. Stefaniak, E. Raymundo-Piñero, F. Beguin, Solvent-free ionic liquids as in situ probes for assessing the effect of ion size on the performance of electrical double layer capacitors, Carbon, 44 (2006) 3113-3148.

[34] N. Suresh, T. Mahesh, K. Manoj, Use of mesoporous conductive carbon black to enhance performance of activated carbon electrodes in capacitive deionization technology, Desalination 268 (2011) 182-188

[35] I. Villar, D.J. Suarez-De la Calle, Z. González, M. Granda, C. Blanco, R. Menéndez, R. Santamaría, Carbon materials as electrodes for electrosorption of $\mathrm{NaCl}$ in aqueous solutions, Adsorption 17 (2011) 467-471.

[36] C. Tsouris, R. Mayes, J. Kiggans, K. Sharma, S. Yiacoumi, D. DePaoli, S. Dai, Mesoporous Carbon for Capacitive Deionization of Saline Water, Environ. Sci. Technol. 45 (2011) 10243-10249.

[37] B.H. Park, J.H. Choi, Improvement in the capacitance of a carbon electrode prepared using water-soluble polymer binder for a capacitive deionization application Electrochim. Acta 55 (2010) 2888-2893.

[38] M. Noked, E. Avraham, A. Soffer, D. Aurbach, The Rate-Determining Step of Electroadsorption Processes into Nanoporous Carbon Electrodes Related to Water Desalination, J. Phys. Chem. C. 113 (2009) 21319-21327.

[39] J. M. Miller, B. Dunn, Morphology and Electrochemistry of Ruthenium/Carbon Aerogel Nanostructures, Langmuir 15 (1999) 799-806.

[40] X.M. Liu, R. Zhang, L. Zhan, D.H. Long, W.M. Qiao, J.H. Yang, L.C. Ling, Impedance of carbon aerogel/activated carbon composites as electrodes of 
electrochemical capacitors in aprotic electrolyte, New Carbon Mater.; 22 (2007) 153158.

Table 1. Main physicochemical and textural parameters of the studied samples.

\begin{tabular}{|c|c|c|c|c|}
\hline & AG25 & AG50 & AG100 & AG200 \\
\hline $\mathrm{S}_{\text {BET }}\left[\mathrm{m}^{2} \mathrm{~g}^{-1}\right]$ & 455 & 760 & 820 & 830 \\
\hline $\mathrm{V}_{\text {TотаL }} \mathcal{S}_{\left[\mathrm{cm}^{3} \mathrm{~g}^{-1}\right]}$ & 0.26 & 0.59 & 0.95 & 1.33 \\
\hline $\mathrm{V}_{\text {MICRO (DR) }}{ }^{\dagger}\left[\mathrm{cm}^{3} \mathrm{~g}^{-1}\right]$ & 0.17 & 0.35 & 0.29 & 0.31 \\
\hline $\mathbf{V}_{\text {MICRO }} / \mathbf{V}_{\text {MESO }}$ & 1.9 & 1.5 & 0.4 & 0.3 \\
\hline Capacitance $^{\#}\left[\mathrm{~F} \mathrm{~g}^{-1}\right]$ & 56.8 & 93.6 & 85.9 & 133.9 \\
\hline \multicolumn{5}{|l|}{$\boldsymbol{\S}_{\text {evaluated at } p / p_{o}} \sim 0.99$} \\
\hline \multicolumn{5}{|c|}{ 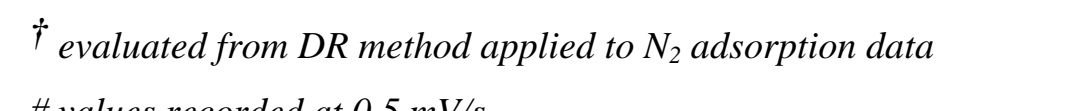 } \\
\hline
\end{tabular}

Table 2. Electrical resistances of carbon aerogel samples as calculated by fitting their impedance spectra.

\begin{tabular}{llll}
\hline Sample & $\begin{array}{l}{[\mathrm{NaCl}]} \\
(\mathrm{g} / \mathrm{L})\end{array}$ & $\begin{array}{l}\mathrm{R}_{\text {solution }} \\
(\Omega \times \mathrm{g})\end{array}$ & $\begin{array}{l}\mathrm{R}_{\text {porosity }} \\
(\Omega \times \mathrm{g})\end{array}$ \\
\hline AG25 & 10 & 0.068 & 1.93 \\
AG50 & 10 & 0.068 & 1.33 \\
AG100 & 10 & 0.052 & 1.13 \\
AG200 & 10 & 0.037 & 0.64 \\
AG200 & 1.5 & 0.131 & 2.97 \\
AG200 & 35 & 0.008 & 0.15 \\
\hline
\end{tabular}




\section{Figure captions}

Figure 1. A) $\mathrm{N}_{2}$ adsorption isotherms at $77 \mathrm{~K}$ of the carbon aerogels samples; B) Pore size distribution evaluated from the DFT method.

Figure 2. Correlation between textural features of the carbon aerogels and their $\mathrm{R} / \mathrm{C}$ ratio; Lines are guides to the eye.

Figure 3. Cyclic voltammograms recorded at several sweep rates in a $\mathrm{NaCl}$ solution of $10 \mathrm{~g} / \mathrm{L}$.

Figure 4. Capacitance calculated from impedance spectra versus frequency in a $\mathrm{NaCl}$ solution of $10 \mathrm{~g} / \mathrm{L}$.

Figure 5. Nyquist plots from impedance spectra recorded for the carbon aerogels in a $\mathrm{NaCl}$ solution of $10 \mathrm{~g} / \mathrm{L}$.

Figure 6. A) Normalized chronocoulometric curves obtained by anodic polarization of carbon aerogel in a $\mathrm{NaCl}$ solution of $10 \mathrm{~g} / \mathrm{L}$; B) correlation between time constant and textural features. Lines are guides to the eye.

Figure 7. Cyclic voltammograms of AG200 carbon aerogel at $1 \mathrm{mV} / \mathrm{s}$ in $\mathrm{NaCl}$ solution of different concentration. Inset: Capacitance versus $\mathrm{NaCl}$ concentration plot.

Figure 8. Normalized chronocoulometric curves obtained by anodic polarization of the AG200 carbon aerogel in a $\mathrm{NaCl}$ solutions of different concentration. 

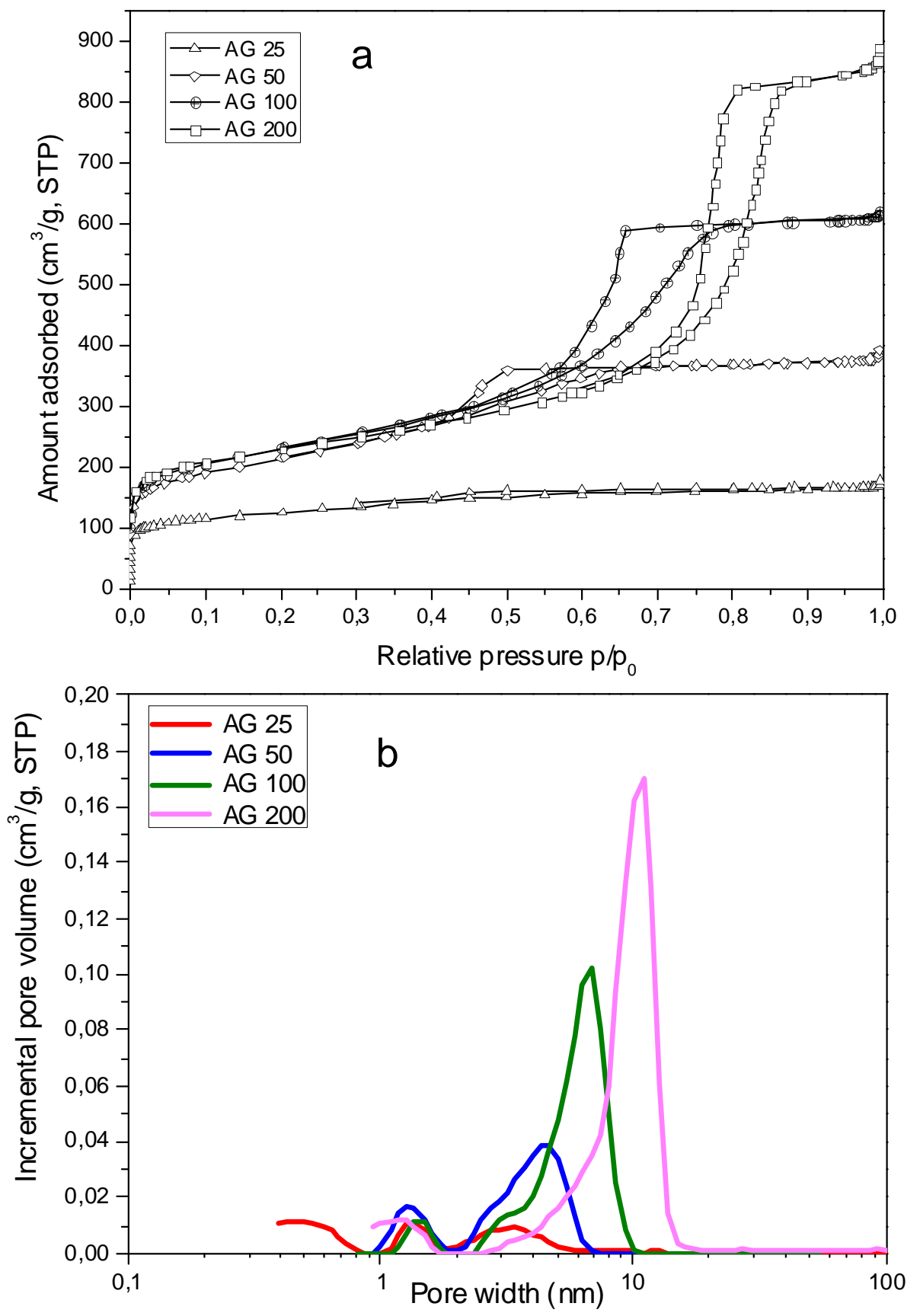

Figure 1 


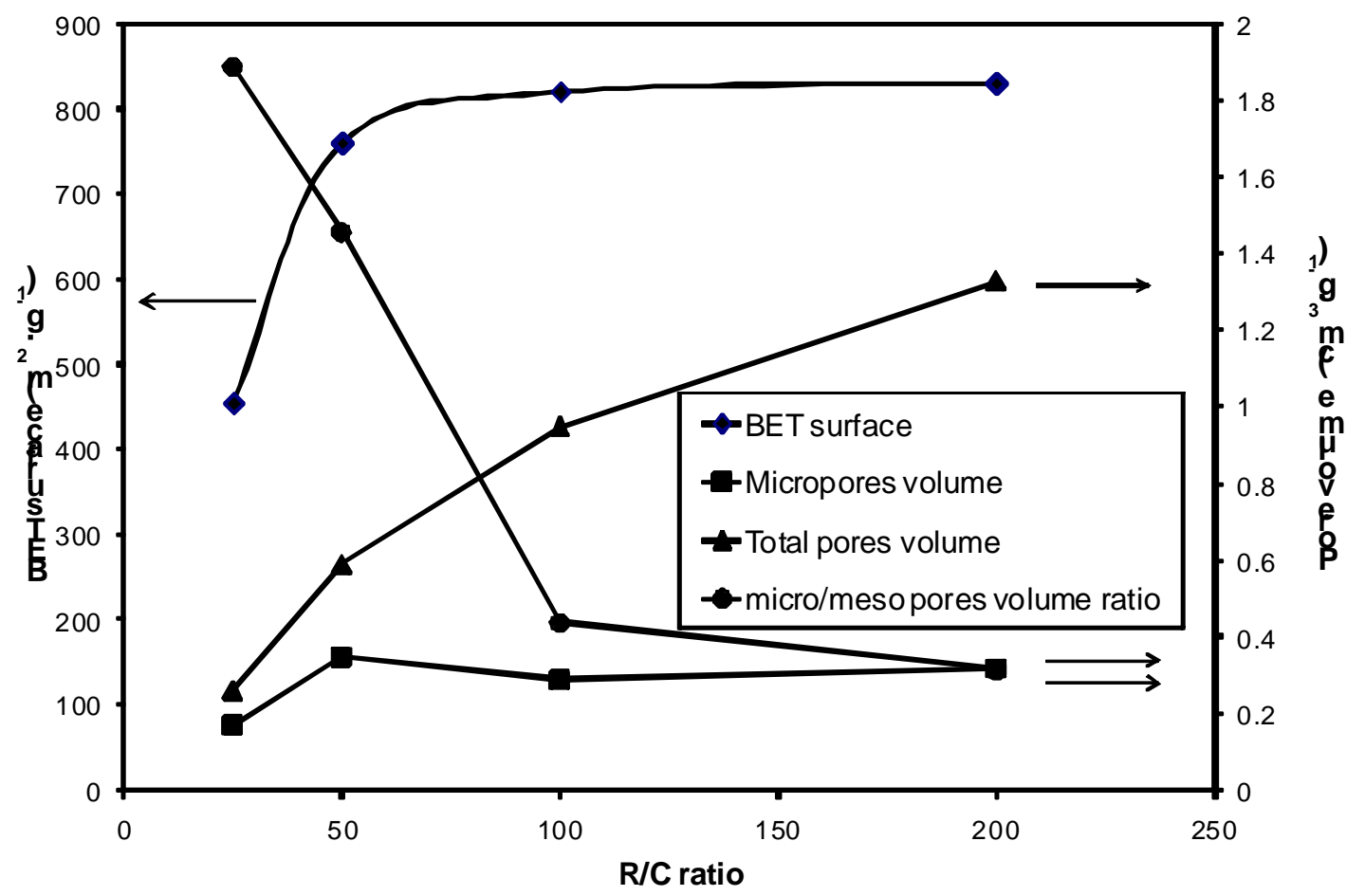

Figure 2 


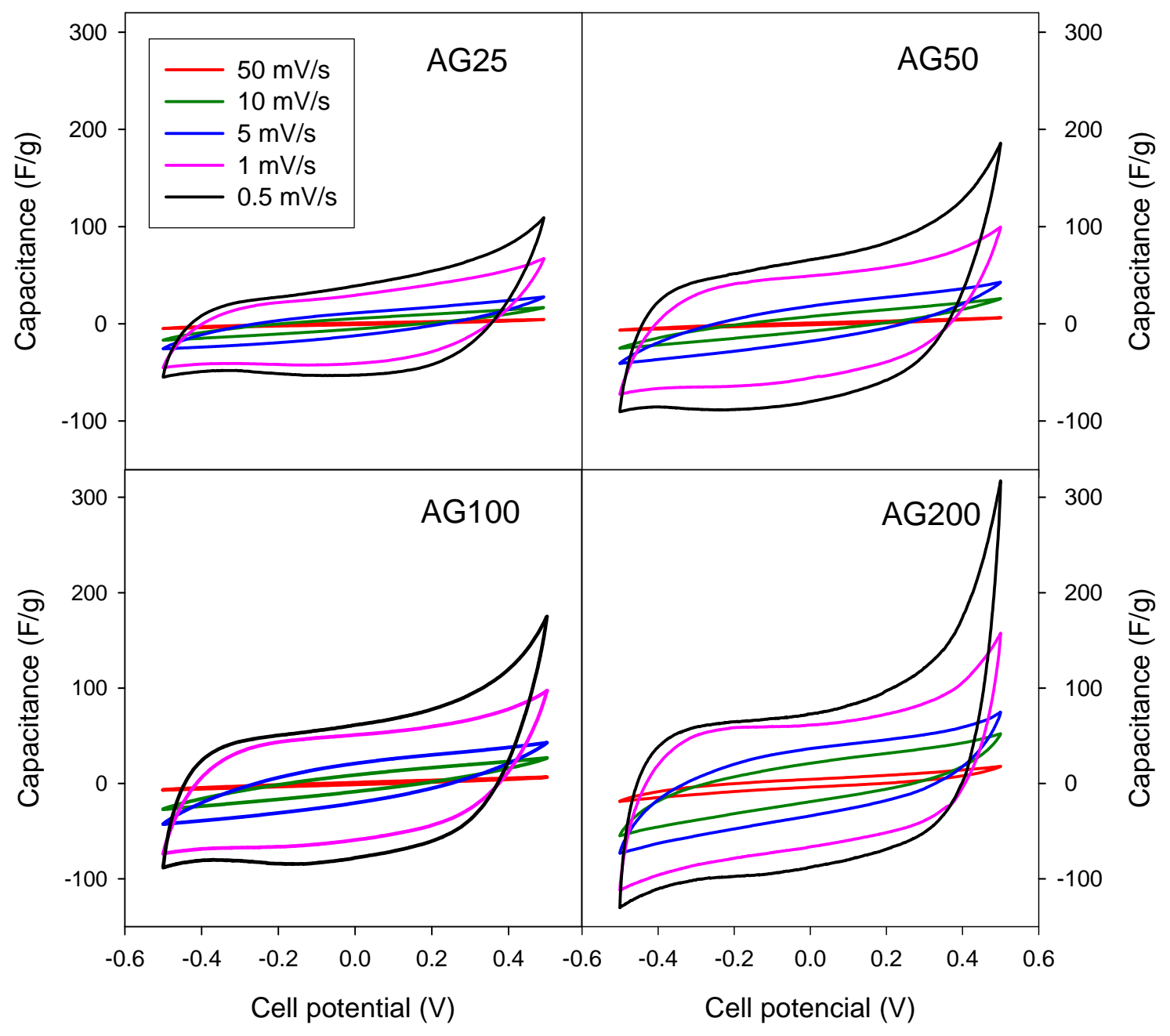

Figure 3 


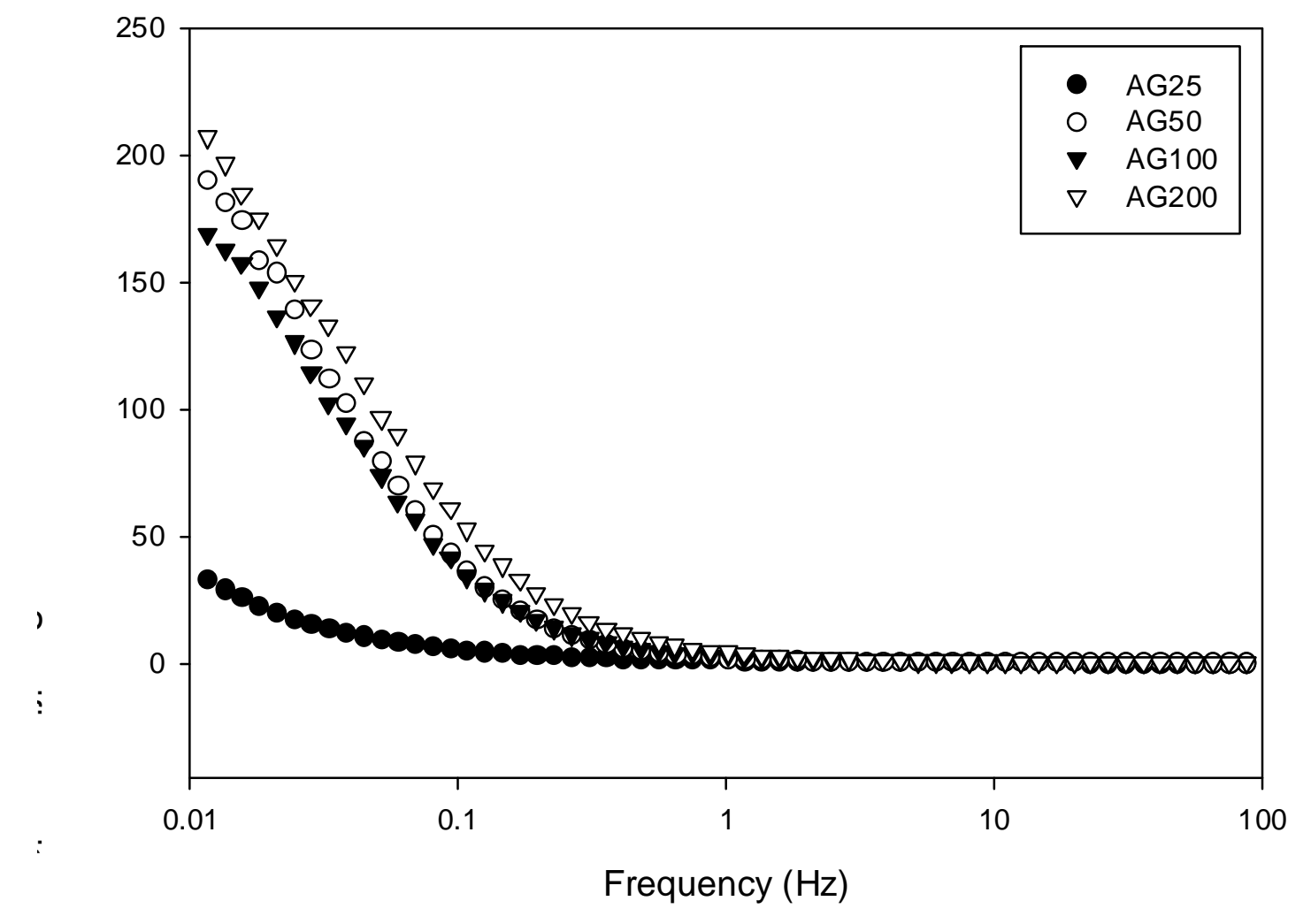

Figure 4 


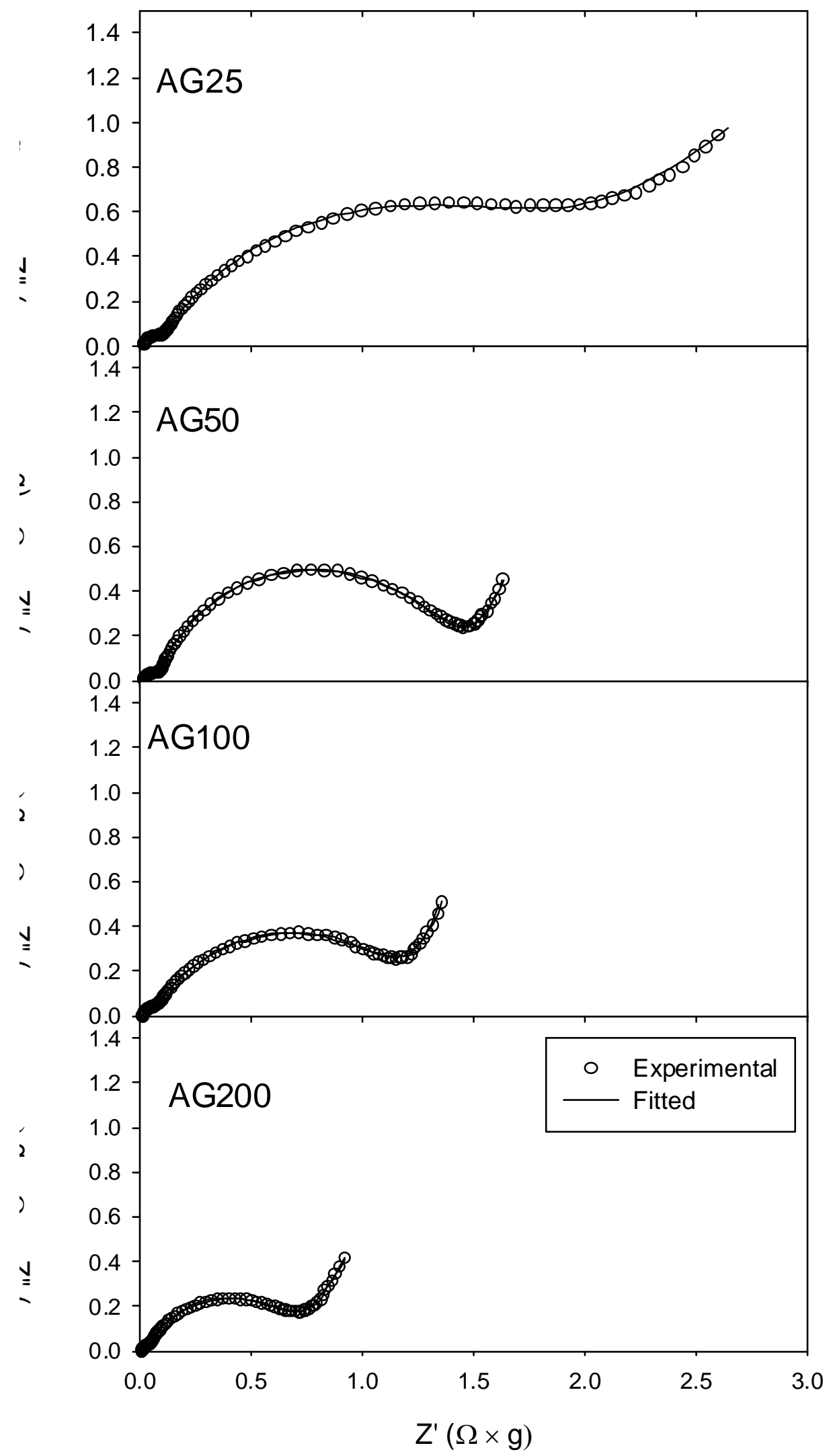

Figure 5 

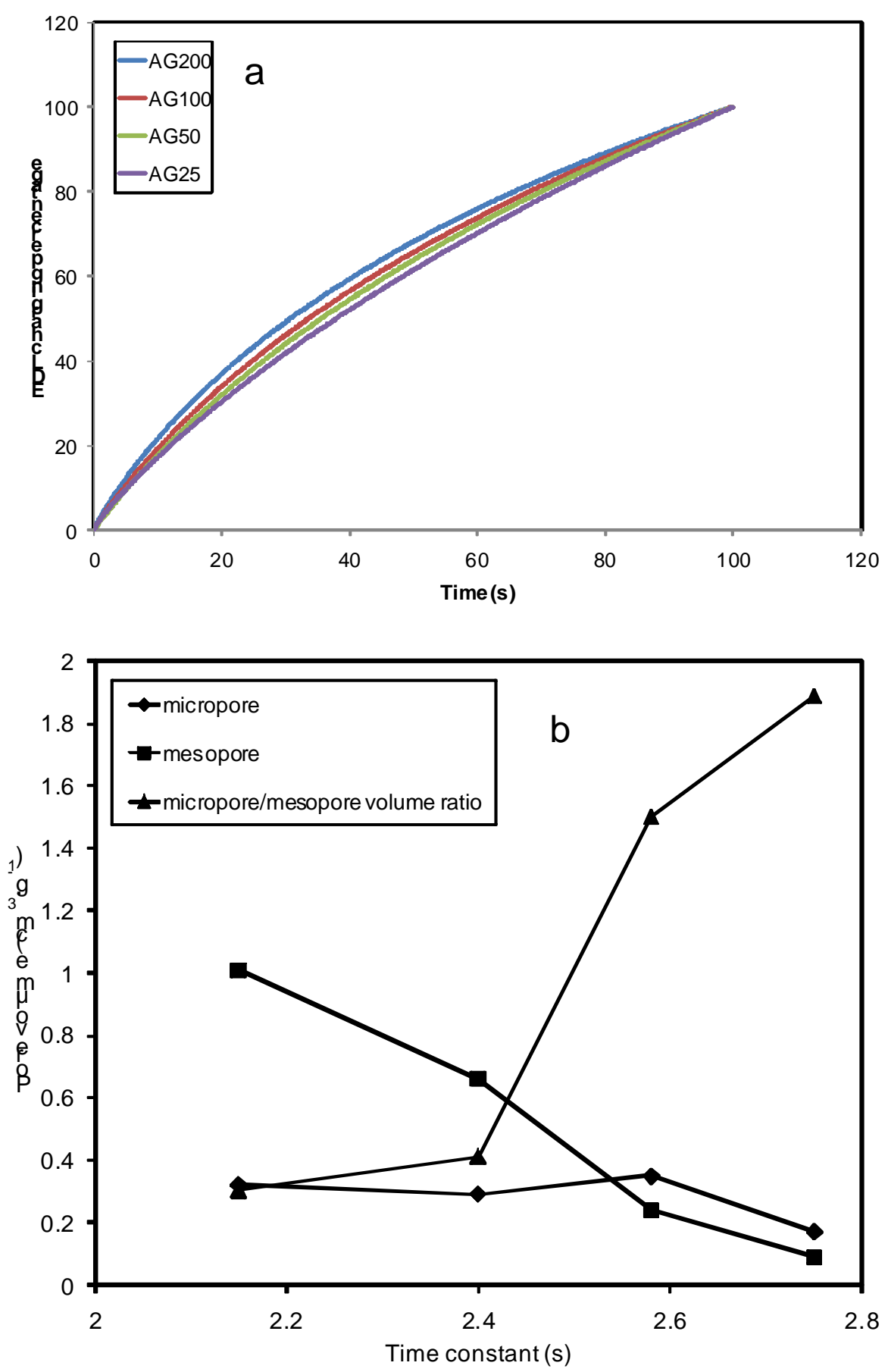

Figure 6 


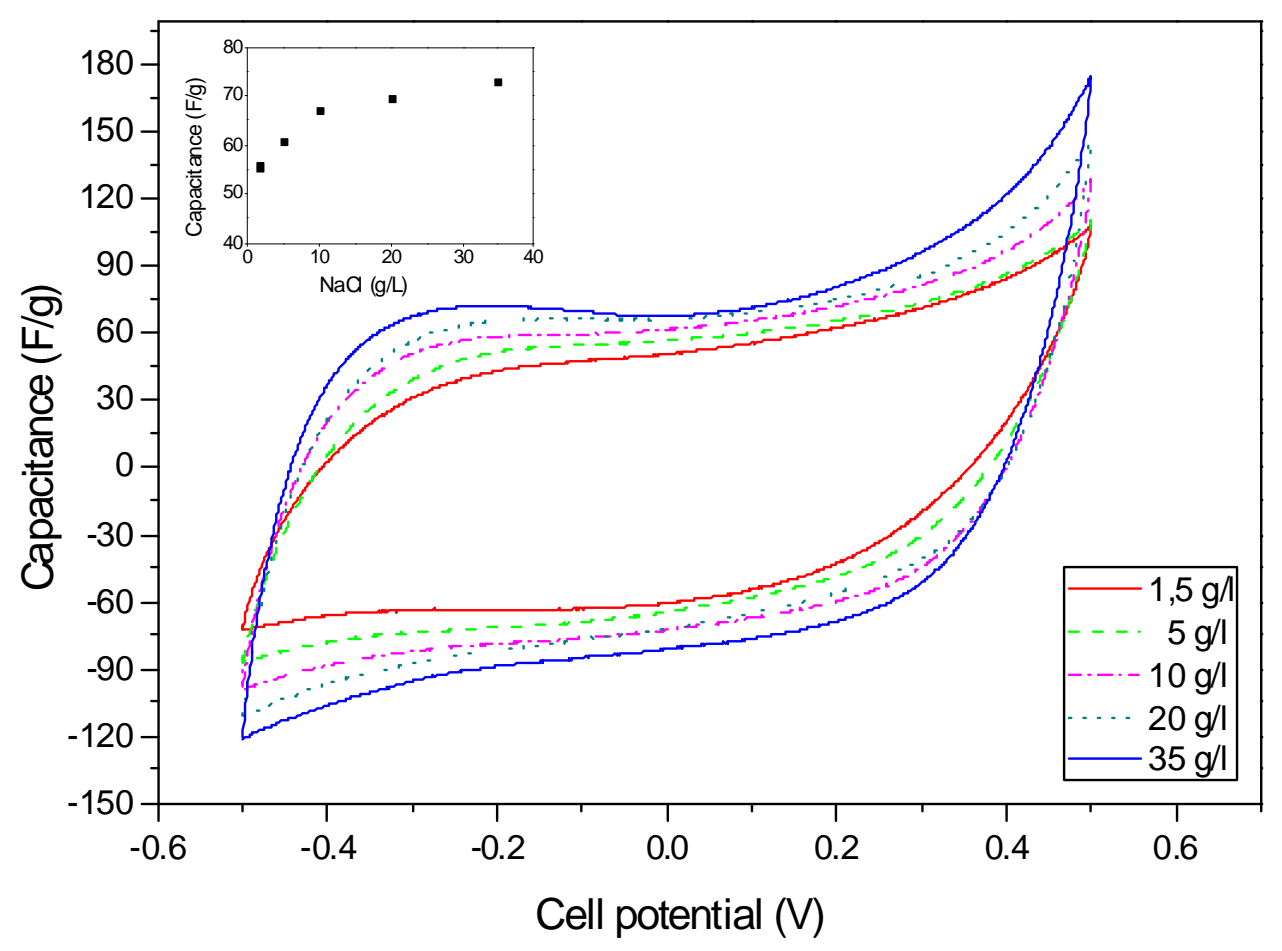

Figure 7 


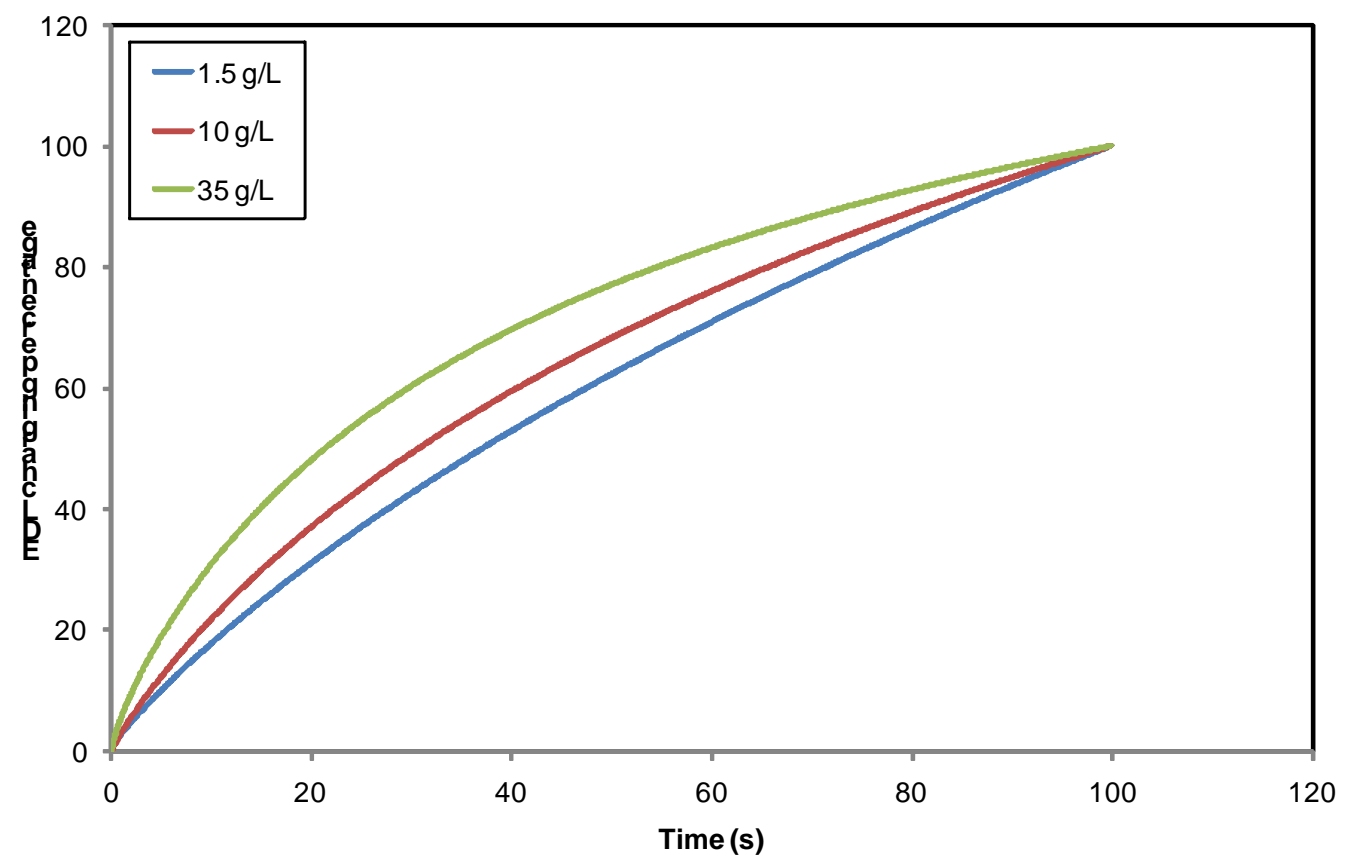

Figure 8 